\title{
Job demands, job decision latitude, job support, and social network factors as predictors of mortality in a Swedish pulp and paper company
}

\author{
N-E ÅSTRAND, B S HANSON, S-O ISACSSON \\ From the Department of Community Health Sciences, Lund University, Malmö, Sweden
}

ABSTRACT Three hundred and ninety one male employees aged 35-65 in a Swedish pulp and paper 3 company were followed up for 22 years; 151 deaths were recorded by 31 December 1983 . On the basisis of data from 1961, indices for job decision latitude, job support, and other work related psychosociakr factors were constructed as were five indices for non-work related social network factors. All indicesw were checked by life table analysis in respect of mortality. Job decision latitude and a combined index $x_{0}^{+}$ for job decision latitude and job support showed significant associations with mortality. These two indices were investigated by multivariate analysis with scale for evaluation of neuroticism and knownz somatic risk factors such as smoking, cholesterol, and systolic and diastolic blood pressure. Age educational level, occupational status, physically heavy work, and general health state were also $\vec{\bullet}$ included in the multivariate analysis. Age, systolic blood pressure, the combined index for jobe decision latitude and job support, smoking, and neuroticism were shown to be independent predictors of mortality.

Work related psychosocial factors have shown an association with mental symptoms, psychosomatic disorders, and cardiovascular morbidity in cross sectional studies. ${ }^{1-4}$ Case-control studies have also shown an association between psychological work demands and lack of influence over the working situation on the one hand and cardiovascular cerebrovascular or cardiovascular mortality on the other. ${ }^{5-6}$

Prospective studies have shown that hectic and psychologically demanding work, low decision latitude, and combinations of these factors are predictors of mental strain and cardiovascular morbidity and mortality. ${ }^{25-8}$

In social epidemiology there is a growing interest in various aspects of social network and social support as determinants of health, including premature death. ${ }^{9-15}$

The theoretical basis for the action of work related psychosocial factors on health has its source in stress research dealing with principally adrenal hormones as mediators of ill health. ${ }^{16-18}$

Karasek has hypothesised that the influence of work demands on health may be moderated by the degree of control the individual has over his work. ${ }^{2}$ This is called

Accepted 18 April 1988 the job strain model. A combination of high work demands and low level of permitted discretion in the control of ones own work carries the highest risk for il? health.

Johnson and Theorell have established the term iso strain to measure the combined exposure to psy⿺ chological work demands, the level for work control 3 and the level for work related social support. ${ }^{3}$ The isostrain model was hypothesised to be the best predicto of cardiovascular morbidity and was shown to have the strongest cross sectional association with cardio vascular morbidity.

The theory for social network and social support research is the "theory of general susceptibility," presented by Cassel in $1976^{19}$ It emphasises a non specific influence of factors in the social environment on the resistance of man against different pathogenic agents.

There is evidence to believe that all factors tha arouse perceived and persistent strain, work relatedo and others, give rise to similar physiological responses⿱ and accordingly act on the same end points. ${ }^{1920}$

The aim of the present study was to examine the predictive power of job demands, job decision latitude job support, and social network factors with reference? to total mortality. 


\section{Material and methods}

The baseline data used here have been described in an earlier report and the end point data in another. ${ }^{21} 22$

Briefly the study group comprised 391 male employees in Svenska Cellulosaaktiebolaget (SCA), a pulp and paper company in the north of Sweden. All men, who at the time of the examination in 1961 were aged $35,45,55$, and 65 or as close to the respective ages as possible, were invited to participate so as to obtain age groups with about 100 men in each. The difference between stipulated and actual age was less than two years in $92 \%$ of the subjects.

All categories of male employees were selected and the overall participation rate was $83 \%$. All employees except manual workers will be referred to as clerks.

The production units had been modernised by gradual stages during the follow up period until 1983. The modernisation entailed an increase in supervisory duties and a decline in continuous physical strain as well as reduced exposure to heat, moisture, cold, draught, and noise.

The individual examination performed in 1961 took one day. Ten subjects a day went through stations for medical, sociological, and psychological examination.

The medical examinations started with a questionnaire, a Swedish modification of the Cornell Medical Index comprising about 200 questions regarding earlier and present symptoms and disorders. ${ }^{23}$ Thirty two questions in the psychiatric part of the questionnaire constituted the Marke-Nyman scale of neuroticism. ${ }^{24}$

The sociological instrument for examination comprised questionnaires on school and training, working conditions, family relations, housing conditions, house keeping, social contacts, leisure activities, financial status, health, and, for the oldest age group, attitudes to retirement.

Five work related indices were constructed on the basis of the questionnaires.

Psychological job demands were referred to simply as job demands. They were defined as hectic and psychologically demanding work. This index was similar to a correspondent index used by Karasek for Swedish data. ${ }^{2}$ The questions used for this and the other indices used in this study are given in an appendix.

The index for experience of arduous physical job demands was constructed on the basis of nine common physical demands and exposures. The theoretical basis for this index was an earlier finding that physical demands, if perceived as strenuous, can predict early retirement. ${ }^{25}$

The job decision latitude index was constructed on the basis of the 1961 questionnaire. It was defined according to Karasek as "the discretion permitted the worker in deciding how to meet the demands."2

Job support describes the subject's relations to superiors and fellow workers. Good relations are assumed to be perceived as good support at work.

The work related social contacts index describes the quality of the relations with fellow workers, social intercourse with fellow workers in leisure time, and experienced interaction with fellow workers during working hours.

Indices for different aspects of non-work related social network and social support were also constructed, mainly in accordance with a model presented by Hanson and Östergren ${ }^{26}$ :

Contact frequency based on frequency of contacts with relatives, friends, neighbours, and fellow workers.

Social anchorage defined according to Hanson and Östergren ${ }^{26}$ covers the degree to which the individual belongs and is anchored within formal and informal groups in the social network and, in a more functional sense, the degree of feeling of membership in these groups. The present index is based on anchorage to place of living, church, clubs, and position of trust in the trade union.

Social participation describes how actively the individual takes part in activities of formal and informal groups in society. ${ }^{26}$

Satisfaction with social contacts reflects the perceived adequacy of contact frequency with relatives, friends, neighbours, and fellow workers.

Availability of emotional support is the individual's own account of his opportunities to get emotional support. ${ }^{26}$

All these indices were handled in the following way: the distribution of answers to each question was dichotomised by the median and given the values zero or one. For each index the values of all pertaining items were summed. The summary distribution of values for each index was again dichotomised by the median for use in analysis.

The psychological examination was performed by one psychologist. Three tests measuring mental abilities were performed. One of them, the most age independent, was used in this study: "synonyms," in Sweden called "SRB:1," a test measuring verbal ability with a reported reliability of $0.95 .^{27}$

Blood pressure was registered from one arm in a supine position. The diastolic pressure was registered on the complete disappearance of sounds (phase 5).

Blood for the analysis of cholesterol was taken in the morning before the intake of food and the analyses were carried out at the local hospital by methods current at the time.

By 31 December 1983, 151 deaths had been recorded. Cause of death was obtained from the National Central Bureau of Statistics. With the exception of 
three emigrants all individuals vital status was reliably established.

The multivariate analysis comprised the independent variables job decision latitude, the combined index for job decision latitude and job support, and the following covariables: age, occupational status as manual worker or "clerk," education measured as years at school, neuroticism, the psychological test synonyms, self assessment of physically heavy work, scales for self assessed health, and the doctor's assessment of general health, height, systolic and diastolic blood pressure, cholesterol, and smoking.

The combined index for job decision latitude and job support was dichotomised by the combination above median for both variables against all other combinations. Age, height, and systolic and diastolic blood pressure, were analysed as continuous variables. Education was dichotomised at the limit for mandatory education, neuroticism by the highest decile of "yes" answers to the 32 questions included in the Marke-Nyman scale, and cholesterol by the limit of $300 \mathrm{mg} / 100 \mathrm{ml}$ blood. Smoking was dichotomised at the limit of smokers and non-smokers. The other independent variables were dichotomised by the median.

\section{STATISTICAL METHODS}

Univariate analyses of the indices for job decision latitude, job demands, and social contacts and combined indices were performed by use of life table analysis.

Cox regression analysis was used for the multivariate analysis.

\section{Results}

Figure 1 shows the cumulative mortality by job decision latitude above and below the median. The index measuring job decision latitude was the only one to show a significant predictive power for mortality $(p=0.005)$. The overall mortality during the 22 year follow up for job decision latitude above and below the median was $34 \%$ and $45 \%$ respectively. Analogous analyses were performed for the different age groups. Those aged 65 with job decision latitude below the median showed a significantly higher mortality than the group above $(p=0.033)$. Those aged 55 showed a corresponding significant difference in mortality $(p=0.031)$. Those aged 35 and 45 were analysed together because of their low mortality. The life table analysis of these groups taken together showed a nonsignificant difference in the expected direction $(\mathrm{p}=0 \cdot 115)$.

The indices for job demands, physical job demands, and work related social contacts or job support showed no separate predictive power for mortality.

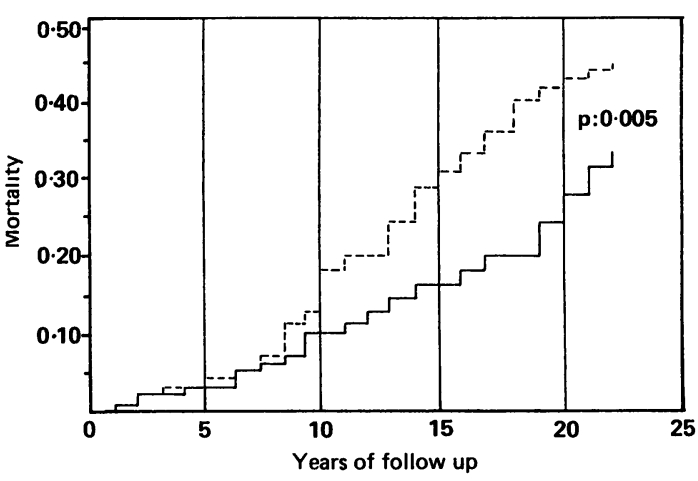

Fig 1 Cumulative mortality 1961-83 by different job decision latitude. Life table analysis.— Job decision latitude above median $(n=209)$; $-\longrightarrow$ Job decision latitude below median $(n=174)$.

Combinations of job demands with job support and work related social contacts respectively had no $\vec{z}$ predictive power either, nor did the combination of job decision latitude with job demands increase the $\vec{\theta}$ predictive power of the first mentioned variable.

The job decision latitude index was then combined with the index for job support (fig 2). Between about 12 and 20 years follow up there is a fair separation of the four lines. Low job decision latitude and low job support have the highest mortality. Low job decision $\stackrel{2}{\circ}$ latitude and high job support come next, followed by $\unrhd$ high job decision latitude combined with low social $\overrightarrow{\vec{A}}$ support. High decision latitude combined with high $\frac{9}{3}$ social support give the best survival rate $(p=0.027)$.

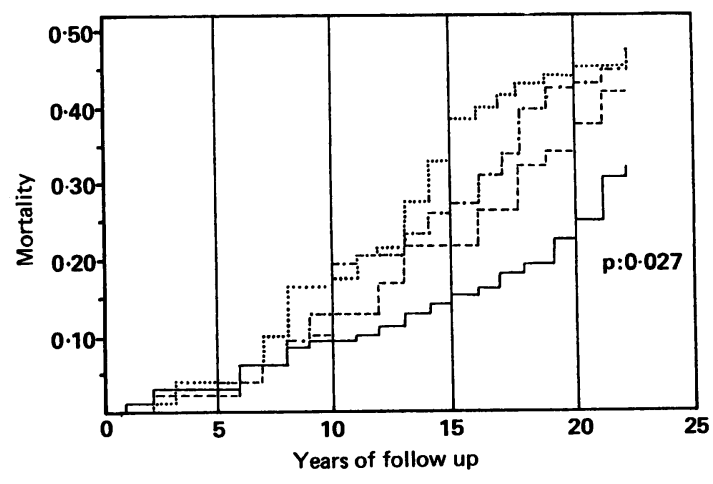

Fig 2 Cumulative mortality 1961-83 by different combinations of job decision latitude and job support. Life table analysis.— Job decision latitude and job support above median ( $n=159)$; - $-J o b$ decision latitude above median and job support below $(n=48)$; - - - Job decision latitude below median and job support above $(n=102) ; \ldots \ldots$ Job decision latitude and job support below median $(n=70)$. 
Table 1 Predictors of mortality. Analysis with covariatesCox models

\begin{tabular}{lll}
\hline Variable & $\begin{array}{l}\text { Relative } \\
\text { risk }\end{array}$ & $\begin{array}{l}95 \% \text { Confidence } \\
\text { interval }\end{array}$ \\
\hline Age & $2 \cdot 3^{*}$ & $1 \cdot 9-2 \cdot 8$ \\
Systolic blood pressure & $1 \cdot 1 \dagger$ & $1 \cdot 1-1 \cdot 2$ \\
Job decision latitude and job support & $1 \cdot 5 \ddagger$ & $1 \cdot 0-2 \cdot 1$ \\
Smoking & 1.6 & $1 \cdot 1-2 \cdot 4$ \\
Neuroticism & 1.6 & $1 \cdot 0-2 \cdot 6$ \\
\hline
\end{tabular}

* Relative risk represents the effect of an increase of 10 years in age. †Relative risk represents the effect of an increase of $10 \mathrm{~mm} \mathrm{Hg}$ in systolic blood pressure.

$\ddagger$ Negative association.

The mortality risk for high job decision latitude combined with high job support at the closing point of the study was $32 \%$ and for the other combinations $42 \%, 46 \%$, and $44 \%$ respectively.

A combination of job demands, job decision latitude, and job support in line with the iso-strain model developed by Johnson and Theorell gave no increase in the predictive power of job decision latitude alone or the combined index of job decision latitude and job support. ${ }^{3}$

The five different indices categorising social network and social support factors showed no predictive power in the univariate analysis.

The index for job decision latitude and the combined index for job decision latitude and job support were analysed with reference to mortality by Cox regression together with 13 covariables listed above under methods; the results are shown in table 1.

Age, systolic blood pressure, the combined index for job decision latitude and job support, smoking, and neuroticism were shown to be independent predictors of mortality during the follow up period.

The relative risk of dying during the observation period was $2 \cdot 3$ for an increase of 10 years in age. Systolic blood pressure showed an analogous relative risk of 1.1 for an increase of $10 \mathrm{~mm} \mathrm{Hg}$. The combined index for job decision latitude and job support showed a relative risk of 1.5 for all combinations of those variables other than those above the median at both. Smoking showed a relative risk of 1.6 and neuroticism a risk of 1.6. Neuroticism showed a borderline significance $(p=0.053)$ at entrance into the equation. The confidence interval did not exceed the limit of $1 \cdot 0$.
Table 2 shows the variation of the variables shown to be independent predictors of mortality.

\section{Discussion}

There was reason to believe that the non-participants were in somewhat worse health than the participants but the magnitude of the non-participation has been assumed not to have biased the present results. ${ }^{21}$

In this study the single independent variables used in the life table analysis were dichotomised at the median. This design was used to obtain sufficient numbers of deaths in every cell when two or three indices were combined.

All single indices were also analysed in trichotomic versions as low, medium, and high. The index for job decision latitude was the only one to show a significant difference in outcome with life table analysis. The trichotomised version of the last mentioned index showed a mortality of $24 \%$ for high and $47 \%$ and $41 \%$ respectively for medium and low job decision latitude. This result indicates a threshold value at a level corresponding to four or more positive answers to the five questions included. No such threshold values can be recognised in the reports presented by Karasek and Johnson. ${ }^{2-3}$

Psychological job demands did not influence mortality in this study. A combination of the variable job demands with job decision latitude in accordance with Karasek's definition of job strain gave no better prediction of mortality than job decision latitude alone.

A combination of job demands, job decision latitude, and job support in accordance with the measure of iso-strain of Johnson and Theorell was also tested but had no better predictive power than the combination of job decision latitude and job support. ${ }^{3}$

The lack of association between job demands and mortality in this study is interesting. Psychological work demands measured as hectic work have shown significant association with indicators of ill health in several reports. ${ }^{2-35-8}$ None of these studies reported a follow up time of more than six years, however.

House et al reported a lack of association between psychological work demands and mortality from the Tecumseh Community Health Study ${ }^{28}$ The follow up time was 9-12 years. In a subsample reinterviewed one

Table 2 Description of the independent predictors in multivariate analysis

\begin{tabular}{|c|c|c|c|c|c|c|c|}
\hline Variable & Yes & $\%$ & No & $\%$ & Min & $\operatorname{Max}$ & Median \\
\hline $\begin{array}{l}\text { Systolic blood pressure } \\
\text { High job decision latitude and high job support } \\
\text { Smoking } \\
\text { Neuroticism (a total sum of } 6 \text { or more yes answers } \\
\text { to } 32 \text { questions) }\end{array}$ & $\begin{array}{r}159 \\
253 \\
45\end{array}$ & $\begin{array}{l}42 \\
65 \\
12\end{array}$ & $\begin{array}{l}220 \\
135 \\
\\
345\end{array}$ & $\begin{array}{l}58 \\
35 \\
\\
88\end{array}$ & 105 & 230 & 140 \\
\hline
\end{tabular}


to three years after the first interview, however, he found an association with subsequent mortality among subjects with moderate to high levels of job pressures or tensions at both interview points. An explanation of the lack of predictive power of job demands in prospective studies with long follow up times may be that job demands are not as stable as job decision latitude and job support in the long term.

The physical job demands index also had no predictive power as regards mortality. The questions were constructed to measure experienced strain of the respective physical factor. A similar index constructed by Gardell did show predictive power as regards early retirement in another group from the same pulp and paper company. ${ }^{25}$

The non-work related social network variables did not show any significant discrepancies with life table analysis and the result was still negative when the variables were tested in trichotimised versions. This result may be compared with prospective studies by Berkman and Syme, Blazer, House et al, Schoenbach et al, and Orth-Gomér and Johnson ${ }^{11-15}$ all of which show associations between different measures of social network or social support and subsequent mortality during follow up periods of 30 months to 13 years.

The lack of association with mortality in this study as regards all five indices; contact frequency, social anchorage, social participation, satisfaction with social contacts, and availability of social support is hard to explain. In part it probably refers to the nonmetropolitan area and the homogeneity of the population, all working in the same company and many belonging to families associated with the company for generations. ${ }^{14}$

The overall character of this environment is one offering the possibility of social support when needed, regardless of contact frequency, social participation, and so on. This is also in agreement with House et al who claim that "it is the lack of any meaningful social relationships or ties which is most deleterious for health."13

The indices in this study have been constructed a posteriori. Methodologically, this is a fault that the present study shares with most other prospective studies. ${ }^{14}$ In this study, however, as in the reports of Schoenbach et al and Orth-Gomér and Johnson, the indices were constructed before testing any of the single variables with reference to separate predictive power for mortality. ${ }^{1415}$

In addition to age and the combined index of job decision latitude and job support, systolic blood pressure, smoking, and neuroticism were shown to be independent predictors of mortality. Systolic blood pressure and smoking are well known risk factors for cardiovascular and all causes death. ${ }^{29} 30$

The effect of neuroticism on mortality is interesting.
The scale used covers different groups of mental symptoms. Neuroticism should be looked on as a $\stackrel{\oplus}{\circ}$ measure of emotional disturbances. ${ }^{31}$ Sims defines neurosis as a psychological reaction to acute or $\stackrel{5}{+}$ continuous perceived stress, expressed in emotion or ${ }^{\circ}$ behaviour, ultimately inappropriate in dealing with $\frac{\bar{\sigma}}{\bar{N}}$ that stress. ${ }^{32}$ Thus neuroticism could be regarded as an $\frac{\bar{\sigma}}{\overline{0}}$ intermediate in the chain of events from the perception $\stackrel{\Phi}{\mathscr{Q}}$ of stress to mortality.

Neuroticism, however, seems to be in part depen

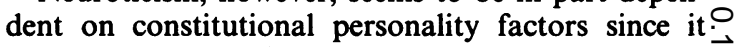
partly correlates with questions in a personality inven- $\overrightarrow{\vec{\omega}}$ tory. ${ }^{33}$

Mortality among psychiatric outpatients and $\mathscr{\mathbb { R }}$ patients with functional disorders has been inves- $?$ tigated earlier. ${ }^{3435}$ In brief the results show an excess $\vec{\sigma}$ mortality from "unnatural" causes related to several or psychiatric diagnoses and symptoms among other $\underset{\omega}{\omega}$ neuroses and cases of alcohol or drug abuse. Sims, $\rightarrow$ however, showed an association between neurosis and $\mathrm{O}$ increased mortality from "natural" causes. ${ }^{32}$

Further investigations into cause specific mortality related to neuroticism in this material is beyond the scope of this study.

Heavy work, occupational status, education, or $\stackrel{\infty}{\oplus}$ health status at baseline did not show any independent 0 predictive power. The investigation of these variables was performed to exclude possible confounders.

Height was included in the equation to test for a constitutional influence on mortality in view of a $\bar{\Phi}$ report by Marmot who found a negative association of $\stackrel{\varrho}{\rightleftharpoons}$ height with mortality and claimed that the influence of $\overrightarrow{\vec{O}}$ height on mortality could be a manifestation of constitution. ${ }^{36}$ No association was found in this study.

The most important conclusion from this study is that in a contemporary industrial population job decision latitude and to a minor degree job support are 3 the outstanding psychosocial factors with long term $\frac{5}{3}$ effects on the health of an individual. Therefore this study is an argument for job redesign that takes into consideration man's need for discretion and influence 2 on his work. It is also an argument for an organisation 음 that creates possibilities for cooperation and interper- $\rightarrow$ sonal support between and among employees.

This study was supported by grant from the Swedish Work Environment Fund.

\section{Appendix}

Questions used for the job demands index:

Can your work in general terms be regarded as hectic?

Do you think that your present work is too hectic and nerve- $\square$ racking?

If it were possible would you change your job for one less strenuous?

Each question was answered yes or no. 
Questions used for the physical job demands index: if "yes" do you find it very trying?

Are you exposed to strong heat?

Are you exposed to severe cold?

Are you exposed to considerable changes between heat and cold?

Are you exposed to dust?

Are you exposed to smoke or gas?

Are you exposed to loud noises?

Does your work force you to strain your eyes?

Does your work require you to lift a lot?

Can your work in general terms be regarded as physically heavy?

Yes answers to both of the questions in a pair yielded the value one.

Other combinations yielded no point.

Questions used for the job decision latitude index:

Can your job in general terms be regarded as one which requires responsibility?

Can your present job be considered as routine or serial production work?

Does your present job require a small or great amount of craftsmanship?

Do you work independently in your present job?

Can your present job be regarded as full of variety?

Each of the five questions provided four ranked alternatives ranked for answer.

Questions used for the job support index:

How do you rate your foreman (nearest superior)?

How do you rate your industrial superintendents?

How do you rate your fellow workers?

Each question provided four ranked alternatives for answer.

Index for work related social contacts:

Do you regard any of your fellow workers as one of your closest friends?

Do you meet any of your fellow workers in your leisure time?

My work has been a way of meeting and socialising with other people.

Questions one and two were answered yes or no. Item three was a rank item investigating the agreement to the present statement in competition with four alternative statements.

Questions used for the contact frequency index:

How often do you see any of your or your wife's relatives? How often do you see any of your friends?

Do you and your neighbours usually visit each other informally?

Do you meet any of your fellow workers in your leisure time?

The first and second questions provided eight alternatives for answer.

The third and fourth questions were answered yes or no.

Questions used for the social anchorage index:

On the whole, how do you like living in this town/neighbourhood?

Are you a member of any religious association, congregation, or organisation?

Are you a member of any other (non-religious) associations, clubs, or organisations?
Do you have any position of trust in the trade union?

Have you planned to leave here and apply for a new job?

The first question provides five alternatives for answer. The second, third, and fourth questions were answered yes or no. The fifth question provided three alterntives to answer.

Questions used for the social participation index:

How often do you go to movies, theatre, discussions, sports competitions or similar entertainments?

About how often do you attend a religious service or any other religious conference or meeting?

Do you generally attend trade union meetings?

How often do you generally attend other association meetings?

The first, second and fourth questions provided six alternatives to answer. The second question was answered yes or no.

Questions used for the index for satisfaction with social contacts:

Do you think that you have too much, too little or just the right amount of contact with your own or your wife's relatives? with your friends? with your neighbours? with your fellow workers?

Each question provided three alternatives to answer.

Questions used for the index for availability of emotional support: Do you regard any of your neighbours as your closest friends?

Do you regard any of your fellow workers as your closest friends? Both questons were answered yes or no.

\section{References}

1 Johansson G, Aronsson G, Lindström BO. Social psychological and neuroendocrine stress reactions in highly mechanised work. Ergonomics 1978;21:583-99.

2 Karasek RA. Job demands, job decision latitude and mental strain, implications for job redesign. Administrative Science Quarterly 1979;24:285-308.

3 Johnson JV. The impact of workplace social support, job demands and work control upon cardiovascular disease in Sweden. (Report No 1.) Stockholm: Department of Psychology, University of Stockholm, Division of Environmental and Organisational Psychology, 1986.

4 Shaw JB, Riskind JH. Predicting job stress using data from the position analysis questionnaire. J Appl Psychol 1983;68: 253-61.

5 Karasek R, Baker D, Marxer F, Ahlbom A, Theorell T. Job decision latitude, job demands and cardiovascular disease: a prospective study of Swedish men. Am J Public Health 1981;71:694-705.

6 Alfreddson L, Karasek R, Theorell T. Myocardial infarction risk and psychosocial work environment: an analysis of the male Swedish working force. Soc Sci Med 1982;16:463-7.

7 Theorell T, Floderus-Myrhed B. "Workload" and risk of myocardial infarction-a prospective psychosocial analysis. Int $J$ Epidemiol 1977;6:17-21.

8 Alfredsson L, Spetz C-L, Theorell T. Type of occupation and nearfuture hospitalisation for myocardial infarction and some other diagnoses. Int J Epidemiol 1985;14:378-88.

9 Cohen S, Syme SL, eds. Social support and health. New York: Academic press, 1985.

10 Isacsson S-O, Janzon L, eds. Social support-health and disease. 
In: Proceedings of sixth international Berzelious symposium in Malmö, Sweden. Stockholm: Almqvist \& Wiksell International, 1986.

11 Berkman LF, Syme SL. Social networks, host resistance, and mortality: a nine-year follow-up study of Alameda county residents. Am J Epidemiol 1979;109:186-204.

12 Blazer DG. Social support and mortality in an elderly community population. Am J Epidemiol 1982;115:684-94.

13 House JS, Robbins C, Metzner HL. The association of social relationships and activities with mortality: prospective evidence from the Tecumseh community health study. Am J Epidemiol 1982;116:123-40.

14 Schoenbach VJ, Kaplan BH, Fredman L, Kleinbaum DG. Social ties and mortality in Evans County, Georgia. Am J Epidemiol 1986;123:577-91.

15 Orth-Gomér K, Johnson JV. Social network interaction and mortality. J Chronic Dis 1987;40:949-57.

16 Karasek A, Russel RS, Theorell T. Physiology of stress and regeneration in job related cardiovascular illness. Journal of Human Stress 1982;8:29-42.

17 Levi L. Work, stress and health. Scand J Work Environ Health 1984;10:495-500.

18 Theorell T. Stress at work and risk of myocardial infarction. Postgrad Med J 1986;62:791-5.

19 Cassel J. The contribution of the social environment to host resistance. Am J Epidemiol 1976;104:107-22.

20 Berkman LF. Assessing the physical health effects of social networks and social support. American Review of Public Health 1984;5:413-32.

21 Åstrand N-E. Medical, psychological, and social factors associated with back abnormalities and self reported back pain: a cross sectional study of male employees in a Swedish pulp and paper industry. Br J Ind Med 1987;44:327-36.

22 Åstrand N-E, Isacsson S-O. Back pain, back abnormalities, and competing medical, psychological and social factors as predictors of sick leave, early retirement, unemployment, labour turnover, and mortality. Br J Ind Med 1988;45:387-95.

23 Brodman K, Erdmann AJ, Wolff HG. Cornell medical indexhealth questionnaire (manual). New York: Cornell University Medical College, 1956.

24 Marke S, Nyman GE. Somatiska och mentala besvär hos en ung normalgrupp. (Somatic and mental complaints in a young population.) Socialmedicinsk Tidskrift 1961;38:315-23. (In Swedish.)

25 Åstrand N-E, Isacsson S-O, Olhagen G. Prediction of early? retirement on the basis of a health examination. An eleven-year $\Rightarrow$ follow up of 264 male employees in a Swedish pulp and paperç? company. Scand J Work Environ Health 1988;14:110-7.

26 Hanson BS, Östergren PO. Different social network and social support characteristics, nervous problems and insomniatheoretical and methodological aspects on some results from the population study "Men born in 1914", Malmö, Sweden. Soc Sci Med (in press).

27 Dureman I, Sälde H. Psykometriska och experimentalpsykologiskaß metoder för klinisk tillämpning. (Studies in psychometric andexperimental methods for clinical evaluation of mental function- ing.) Stockholm: Almqvist \& Wiksell, 1959. (In Swedish.)

28 House JS, Strecher V, Metzner HL, Robbins CA. Occupational stress and health among men and women in the Tecumseh Community Health Study. Journal of Health and Sociald Behaviour 1986;27:62-77.

29 Kannel WB. Some lessons in cardiovascular epidemiology from $A$ Framingham. Am J Cardiol 1976;37:269-82.

30 Conti S, Farchi G, Menotti A. Coronary risk factors and excess or mortality from all causes and specific causes. Int $J$ Epidemiol $\omega$ 1983;12:301-7.

31 Brodman K, Erdmann J, Lorge I, Gershenson CP, Wolff HG, 을 Caples B. The Cornell Medical Index-health questionnaire.III. The evaluation of emotional disturbances. J Clin Psycholz 1952;8:119-24.

32 Sims A. Neurosis and mortality: investigating an association. $\vec{k}$ Psychosom Res 1984;28:353-62.

33 Mori T, Togawu F. Factor analysis of Cornell Medical Index health questionnaires and personality test, questionnaire. Japanese Journal of Hygiene 1980;35:486-92. (In Japanese, summary in English.)

34 Martin RL, Cloninger CR, Guze SB, Clayton PJ. Mortality in a follow-up of 500 psychiatric outpatients. II. Cause-specific mortality. Arch Gen Psychiatry 1985;42:58-66.

35 Black DW, Warrack G, Winokur G. The Iowa record-linkage $\mathbb{D}$ study. III. Excess mortality among patients with "functional" disorders. Arch Gen Psychiatry 1985;42:82-8.

36 Marmot MG, Shipley MJ, Rose G. Inequalities in death-specific 3 explanations of a general pattern. Lancet 1984;i:1003-6. 